\title{
Reconstruction of Perineum and Abdominal Wall
}

\author{
J.J. Vranckx ${ }^{1}$ and A. D'Hoore ${ }^{2}$ \\ ${ }^{1}$ Dept. of Plastic \& Reconstructive Surgery \\ ${ }^{2}$ Dept. Abdominal Surgery \\ KUL Leuven University Hospitals, Leuven \\ Belgium
}

\section{Introduction}

Deep defects at the perineum most frequently result from colorectal or vaginal tumor resection. More superficial but often extensive defects may be caused by radiotherapy, burns or aggressive infections such as necrotizing fasciitis. Resection of colorectal tumors is the main reason for perineal defects that require reconstruction. Abdominoperineal excision of the rectum is largely reserved for larger T2-3 tumors of the distal rectum and poorly differentiated tumors when a safe anastomosis after an anterior resection is not practicable. With the patient in the supine position, the rectum is mobilized down to the pelvic floor via a subumbilical midline incision. After division of the colon, the distal sigmoid is removed as a left iliac fossa colostomy. The distal colon is sutured and folded down into the pelvis. The perineal resection is subsequently performed with the patient in a prone or left lateral position, where utmost care is taken not to allow any tumor spillage by dissecting too close to the rectum. The dissection is therefore performed well into the ischiorectal fossa. The pudendal vessels that supply the anorectal area need to be ligated. For posterior cancers, the coccyx also needs to be resected to provide efficient clearance. In males, damage to the urethra and urethral bulb needs to be avoided. In females, the posterior vaginal wall is resected along with the rectum. These parameters specific to an abdominoperineal rectum amputation determine the difficulty and requirement for reconstruction (Lefevre et al., 2009, Park et al., 2007).

Necrotizing fasciitis of the genito-perineal area (gangrene of Fournier) is a rather frequent cause of extensive tissue loss in the abdominal wall and genitoperineal areas. It is a rapidly progressive mixed infection by hemolytic streptococci or staphylococci and peptostreptococci that is associated with an excessive secretion of toxic metabolites and collagenases that results in the dissolution of connective tissues. These mechanisms make the infection spread rapidly in a suprafascial tissue plane. The infection may be immediately fulminant or initially dormant for some days before evolving rapidly. Typically, no specific port of entry is noted. Because of the suprafacial spreading, the wounds may be extensive but are usually not deep. However, the infection may penetrate through lacerations into muscle compartments or cause a compartment syndrome because of inflammation and 
edema formation. These events may cause secondary destruction of the muscles. Rapid aggressive debridement is the only strategy to halt the necrotizing fasciitis, and repetitive debridements are necessary to stop the progression. Reconstructive options after serial debridement focus on the restoration of the fascioadipocutaneous layers while avoiding tissue contraction.

\subsection{Superficial and extensive defects of the perineal wall}

Superficial extensive defects most often occur after necrotizing fasciitis and seldom occur after burns because this region is well protected by clothing. Serial debridements are required to eradicate the tissue infection. Coverage of the exposed fascia layers and muscle compartments is most commonly performed by split-thickness skin grafts because of the extent of the lesions. To avoid graft contractions, a 1:1 mesh graft pattern is often preferred. Artificial dermal sheets may restore the deep dermal layer and create a more flexible and elastic floor of the wound after skin grafting to prevent tissue contraction in the perineum. Especially in burn treatment, these dermal or skin equivalents have proven their value. The take and integration of these skin equivalents significantly decreases in contaminated areas, and they have no use in infected milieu. Therefore, their use after necrotizing fasciitis is limited. In several countries, there is a partial or total reimbursement for these expensive dermal templates or skin equivalents when the recipient sites are located in the face or over mobile joints. Otherwise, the steep costs may prevent widespread use of these skin equivalents despite their impact on tissue elasticity. In the genitoperineal area, tissue flexibility is important because tissue contraction in the lower abdomen, groin and genitoperineal zones could lead to chronic pain and tissue breakdown as well as loss of function during stance and mobilization. Ideally, a restoration with like-with-like elastic tissues is preferred for deeper defects. Local or locoregional flaps can provide all required donor tissues in this area. The rectus femoris flap has been widely reported to restore groin defects, but this flap can also reach the perianal and perineal areas. It may be estimated that donor site morbidity after prelevation of the rectus femoris muscle is more significant than occurs after harvest of the anterolateral thigh flap in conjunction with a vastus lateralis segment because the rectus femoris is considered the most significant quadriceps muscle. The scar after the prelevation of the rectus femoris flap is located on the anterior thigh and may flatten the natural aesthetic curvature. Depending on the BMI of the patient and skin elasticity, a skin paddle of approximately $7-10 \mathrm{~cm}$ can be harvested from the anterior thigh. To maintain the leverage of the quadriceps tendons for knee extension, it is important not to harvest the flap too distally on the thigh. The tendinous extensions of the vastus medialis, intermedius and lateralis should be reinforced after a rectus flap is harvested distally to preserve the strength of the quadriceps muscles (fig. 1).

The anterolateral thigh flap also offers ample tissues and is an excellent option for defects in the groin and perineum (Friji et al., 2010, Lannon et al., 2011). Its wide arc of rotation, with a pivot point medial to the sartorius muscle, allows an efficient transfer to the perineal floor. Because it is harvested as a fasciocutaneous or adipocutaneous perforator flap, the donor site is minimal in size. Care must be taken not to harm femoral nerve branches to the rectus femoris when the ALT is tunnelled medially under the rectus 
femoris and sartorius. However, without this maneuver, the flap will not be long enough to reach the perineal area.
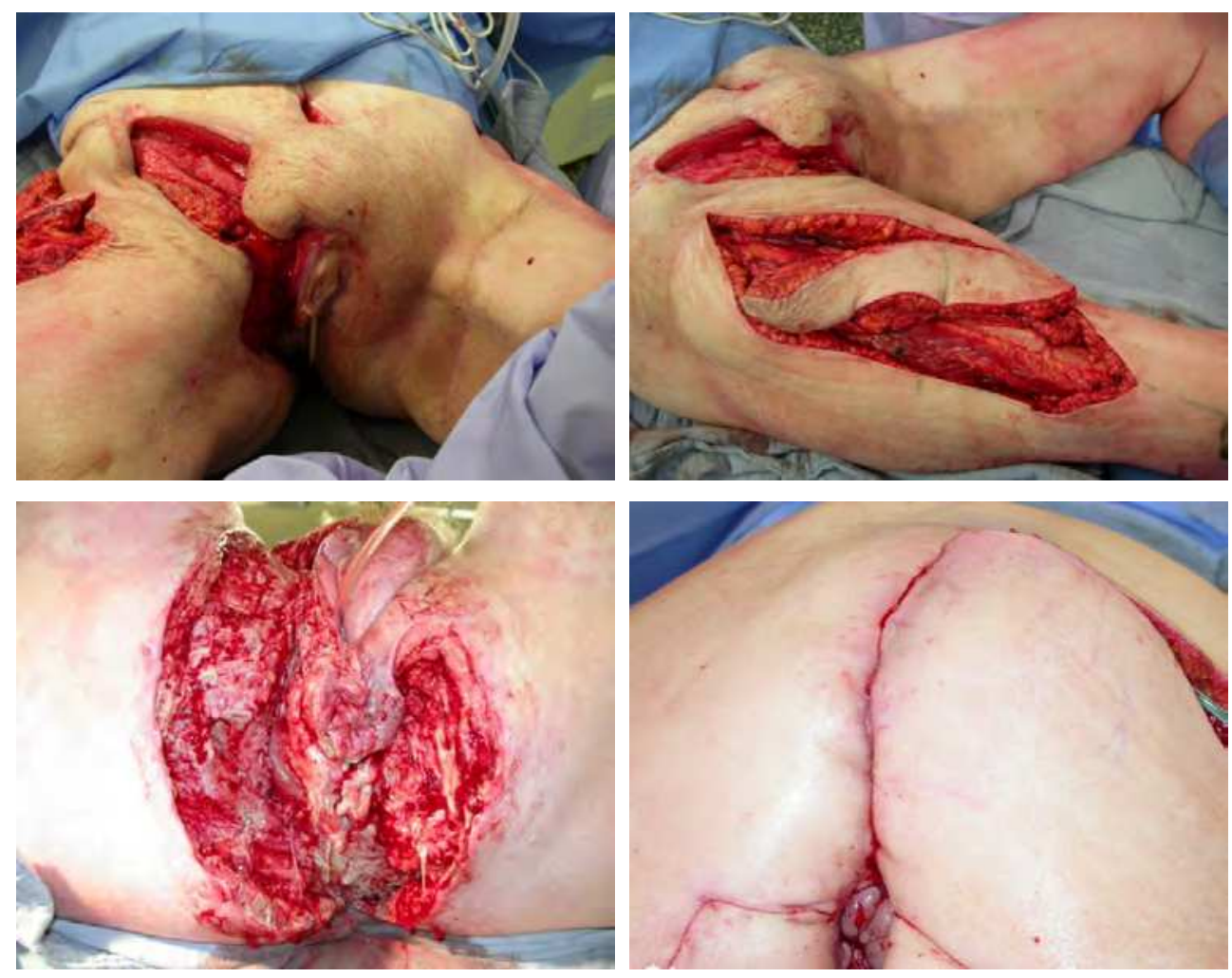

Fig. 1. Necrotizing fasciitis involving the groin and perianal region, sacral and gluteal zones. Upper row: rectus femoris myocutaneous flap harvested for closure of the deep inguinal defect. Lower row: A unilateral inferior gluteal artery perforator flap (IGAP) is dissected to close the sacral and perianal defects. A contralateral SGAP-based flap closes the transition zone between the perianal area and the groin.

For perianal defects and more posteriorly located defects in the gluteal crease and sacral areas, the gluteus maximus myocutaneous transposition flap has been the procedure of choice for decades (fig. 1). This flap can be rotated into the defect as a wide rotation flap or as a V-Y transposition flap. When considering donor site morbidity after harvesting the gluteus maximus muscle, muscle-sparing techniques are the procedure of choice. Flaps in the gluteal area can be harvested based on perforators of the superior (S-GAP) or inferior (IGAP) gluteal vascular pedicle (Wagstaff et al., 2009). Because of an advantageous arc of rotation, the inferior gluteal artery perforator-based flap can be used to address large sacral and perineal defects (Fig. 2). 

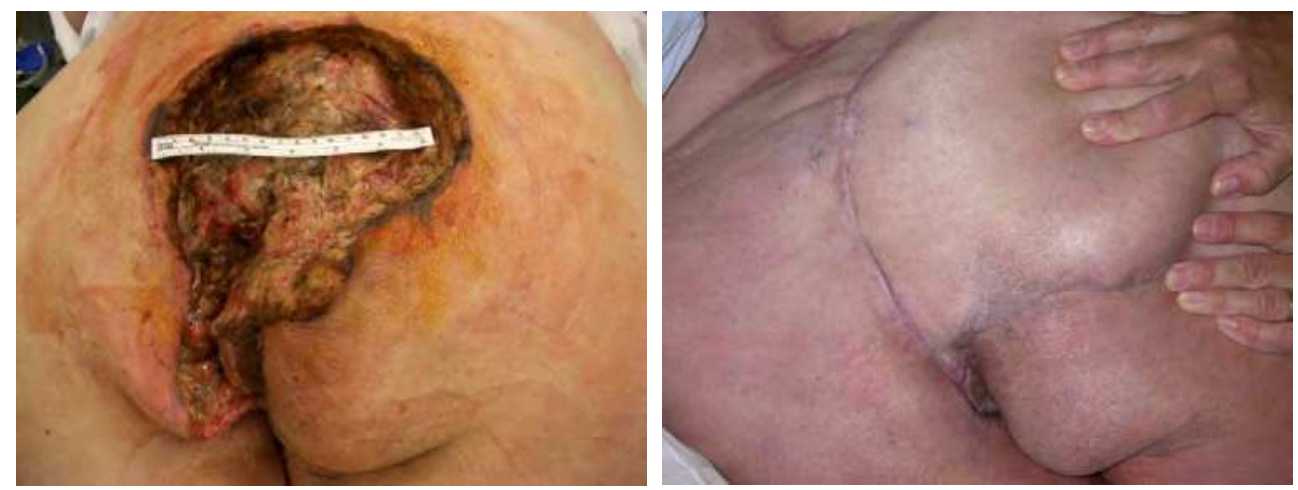

Fig. 2. Necrotizing fasciitis in the perianal area and sacral zones, reconstructed with a unilateral IGAP-based gluteal flap.

\subsection{Defects of the anterior or posterior vaginal wall}

For congenital vaginal aplasia with an intact vaginal canal, the Abbe-McIndoe procedure represents the easiest and most successful method for vaginal reconstruction because it does not require laparotomy. Split-thickness skin grafts are sutured around a vaginal stent with the epithelial side inward (Lesavoy \& Carter , 1996). Patients should wear a conformer for 6 months to avoid contraction off the vaginal vault. Lubricants should prevent the grafts from drying, blistering, and eroding.

Primary sarcomas of the vaginal wall may result in deep vaginal defects of any size and orientation. Skin-grafting techniques using fine 1:1 meshed split-thickness skin grafts function well for superficial defects. However, to prevent tissue contraction and provide appropriate sensitivity in this sensitive area, local and locoregional fasciocutaneous flaps are preferred.

A traditional algorithm for vulvovaginal reconstruction distinguishes between partial IA and IB versus circumferential type II defects (Pusic \& Mehrara, 2006). For partial type IA anterior or lateral defects, pudendal thigh flaps are the first choice for treatment because they provide well-vascularized innervated flaps based on the posterior labial vascular pedicle and the posterior labial branches of the pudendal nerve. The axis of these flaps lies within the groin creases and therefore leaves no donor site morbidity. During the harvesting, it is necessary to incise at both sides into the subcutis at the entrée of the pedicle and in a superficial plane above the pedicle. This maneuver facilitates rotation and donorsite closure. Flap inset is performed by tunneling under the labia majora to avoid creating dog ears in the skin at the pivot points.

Partial type IB posterior defects can also be reconstructed with a pudendal thigh flap. A perforator-based gluteal crease flap can also be harvested in a unilateral or bilateral fashion to allow restoration of the posterior or lateral wall with well-vascularized fasciocutaneous tissues with minimal donor site morbidity. For the reconstruction of an entire posterior vaginal wall, bilateral pudendal thigh flaps or bilateral gluteal crease flaps are required. 
Type II defects are circumferential and are divided to type IIA upper 2/3rd defects and type IIB total defects of the vagina. Most often, such defects are the result of advanced colorectal cancer, advanced cancer of the urinary bladder, primary sarcomas of the vaginal wall or extensive uterine or cervical neoplasms. A resection to negative oncologic borders may result in a cavity. Aside from restoration of the vaginal wall, tissue bulk is required to fill the cavity and avoid herniation of tissues within the cavity, infection, tissue breakdown and fistulization. In such situations, bilateral myocutaneous gracilis flaps are a good option. Segmental or total vaginal defects can be restored with the skin paddle whereas the muscle provides limited tissue bulk to fill a medium-sized cavity (Whetzel \& Lechtman, 1997). The skin island overlaying the gracilis muscle at the medial thigh is not always distally reliable, which may lead to segmental skin necrosis of the distal tip. Incorporation of more fascia at the sides may prevent skin perforators from being harmed during flap harvest (Fig. 3). As a bilateral flap, the gracilis is efficient in restoring defects along the labia majora of the outer vaginal wall. The length from the medial circumflex femoral pedicle to the gracilis determines the arc of rotation. This pedicle should be dissected to the origin at the deep femoral pedicle to allow maximal mobilization of the flaps.
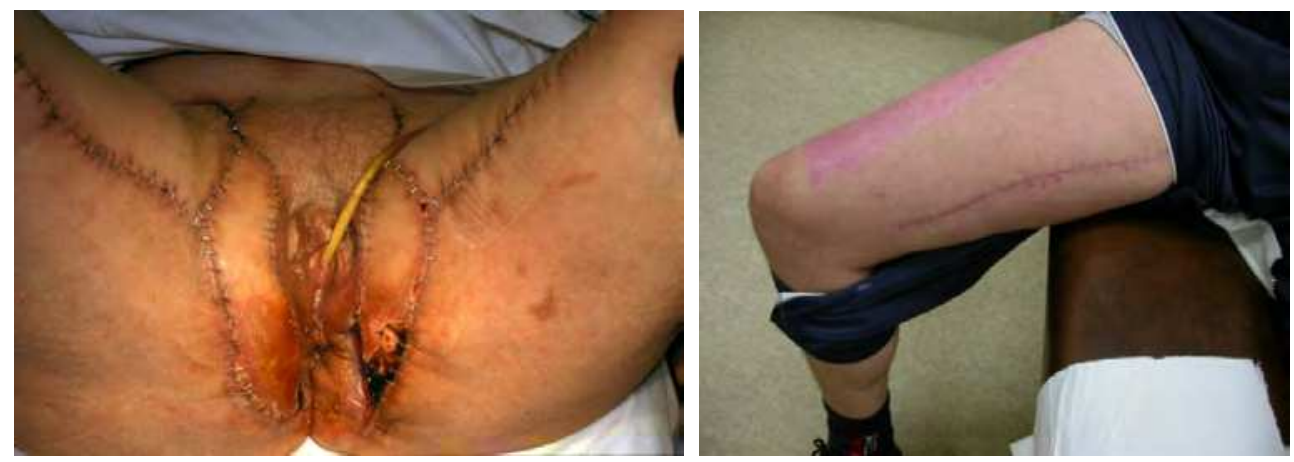

Fig. 3. Left: Bilateral gracilis musculocutaneous flaps restored the perineal wall and labia majora. The left distal skin island of the gracilis flap underwent necrosis. Right: limited donor site morbidity of a gracilis flap.

Often, however, the resection of advanced colorectal cancer leaves a deep cavity with a large risk of herniation of the bowels into the defect. After postoperative radiotherapy, there is a high incidence of fistulization if the cavity is not filled with bulky, well-vascularized tissues. These donor tissues also need to restore the posterior vaginal wall defect. An inferior gluteal artery perforator flap (IGAP) has a broad arc of rotation. A unilateral IGAP flap can be rotated medially, segmentally deepithelialized and set into the defect (Fig. 4). The most medially located segment can be left as a fasciocutaneous unit and used to close a segmental vaginal wall defect.

The primary choice for deep defects including those of the posterior vaginal wall is the vertical rectus abdominis musculocutaneous flap (VRAM), even when a colostomy and urostomy need to be placed in the abdominal wall. (Tobin \& Day, 1988). The VRAM flap is harvested in an anterior fascia-sparing technique that facilitates donor-site closure. A transabdominal-transperineal approach transfers the VRAM flap through the perineal introitus and fills the perianal cavity after colorectal resection with bulky, well-vascularized 

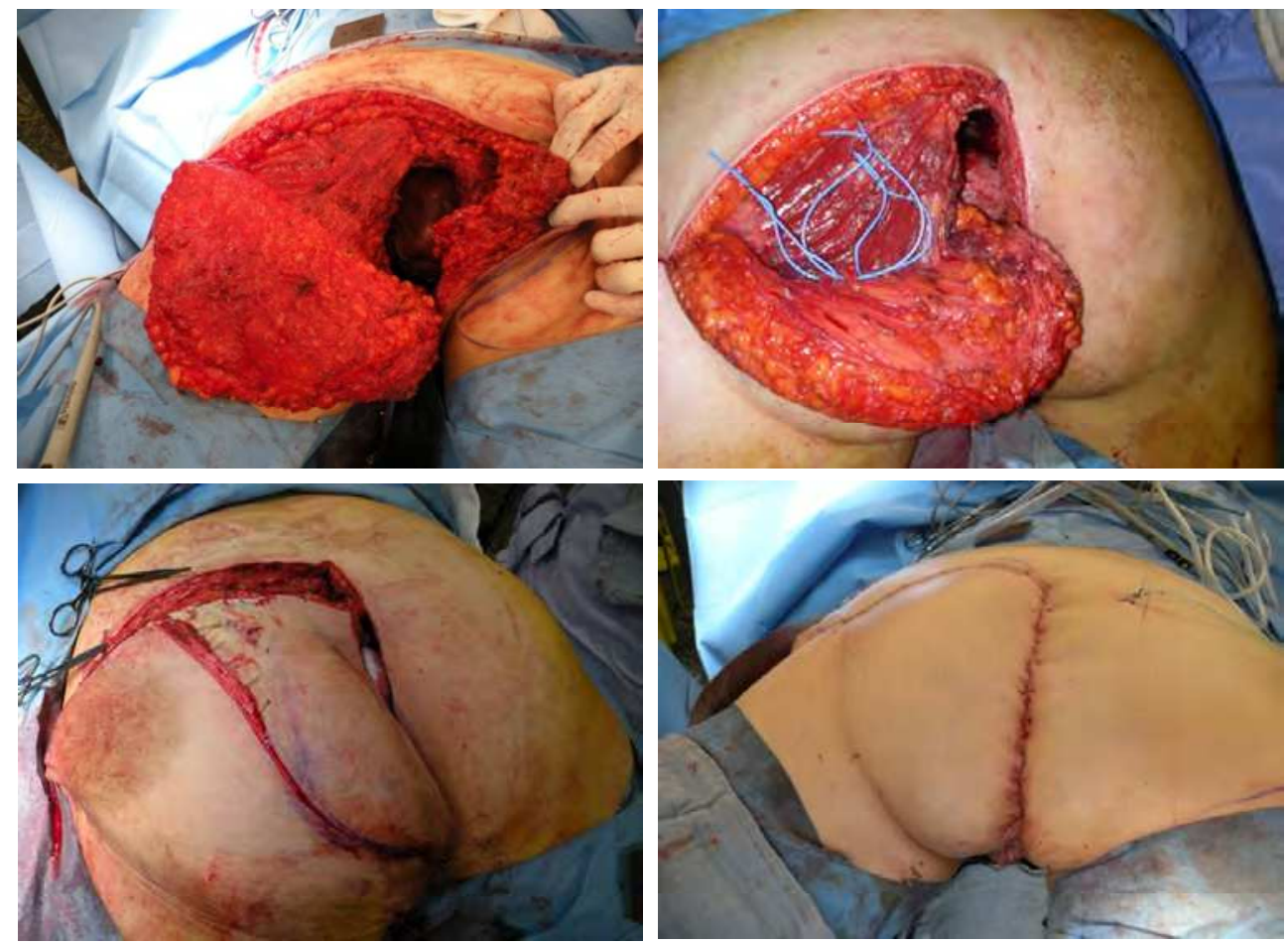

Fig. 4. Upper row: IGAP harvest for perineal reconstruction. Perforators marked with blue vessel loops. Lower row: The medial segment is deepithelialized and introduced into the defect. The contralateral buttock is sutured end-to-side to the IGAP flap at the lateral border of the deepithelialized area.

tissues (Fig. 5). The skin paddle can be located vertically on the mesogastrium over the proximal rectus abdominis muscle. Oblique and extended VRAM flaps based on perforators at the costal margin or at the distal mammary artery are reported. These modifications in the design of the skin island allow the physician to raise the skin paddle more proximally to reach defects located far up in the gluteal crease after transpelvic transfer (Taylor et al., 1993;Abbott et al., 2008 ;Villa et al., 2011). When the rectus abdominis muscle is harvested with a transverse skin island (TRAM-flap), a tubular circular neovagina can be created. After harvest, the flap is formed into a cone and transferred through the peritoneum at the origin of the deep inferior epigastric vessels in a transpelvic approach and sutured to a perineal introital incision (Lesavoy \& Carter E, 1996). A pedicled rectus femoris and anterolateral thigh flap can also be used to create a tubular-shaped neovagina. The length of the neovagina depends on tissue elasticity and flap length and bulk. However, it should be marked that the vector of a unilateral anterolateral thigh or rectus femoris flap may distort tissues after inset and does not yield results that are as aesthetically pleasing as those achieved with a rectus abdominis flap. Fig. 6 represents our current algorithm.

For similar reasons, a myocutaneous gracilis flap should be harvested bilaterally, with each flap recreating one half of the neovaginal cone to prevent the distortion of tissues, as when a unilateral flap is used. 

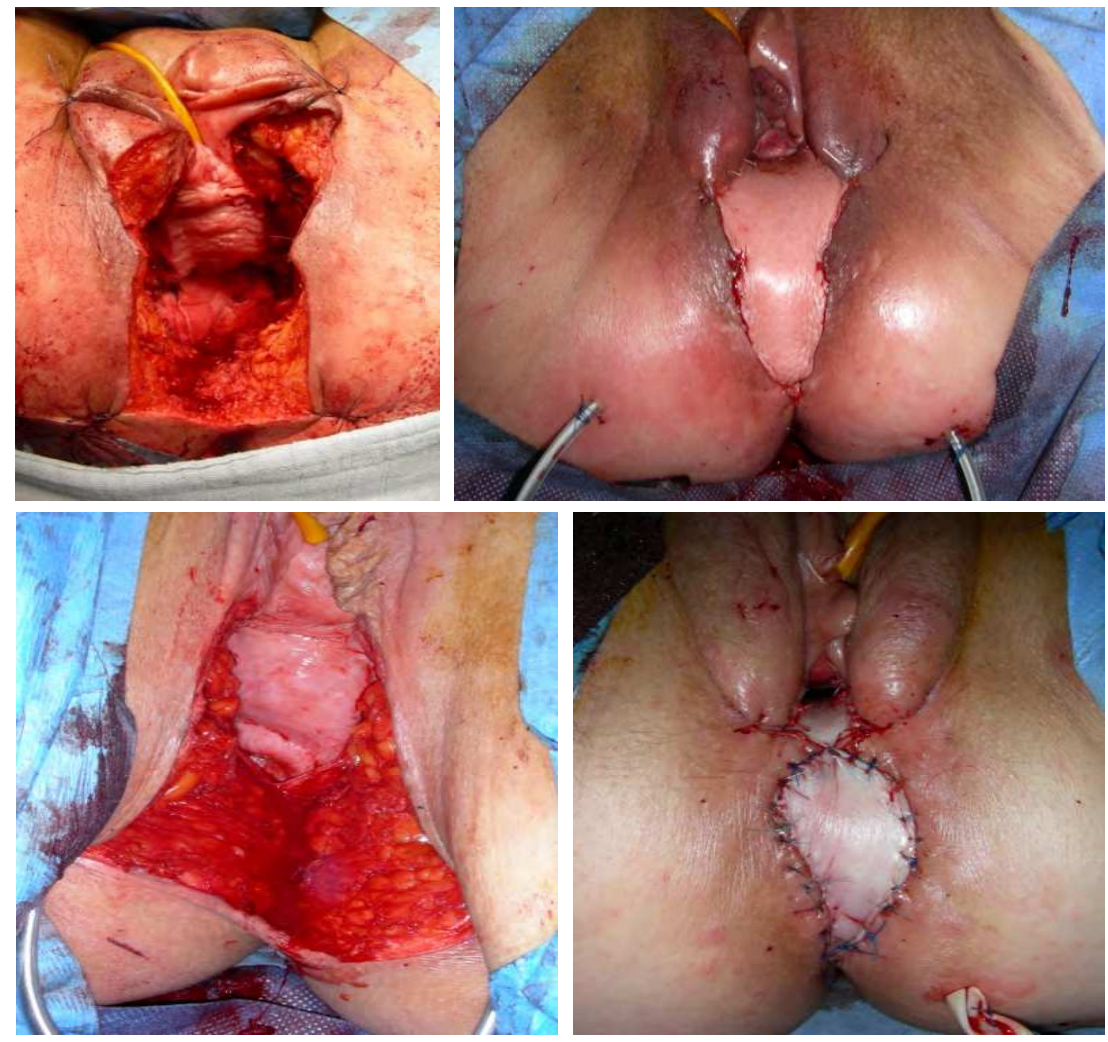

Fig. 5. Posterior vaginal wall defect restored with a vertical rectus abdominis flap by the intraperitoneal transpelvic approach. There is abundant remaining tissue close to the perineal defect. The base of the labia majora is sutured to a deepithelialized segment of the VRAM flap.

\section{Complications}

Infection has an incidence of approximately $10 \%$. Perioperative antibiotics, careful rinsing and meticulous wound-care are mandatory for postoperative care. Irradiation, smoking and obesity are the risk factors most strongly associated with delayed wound healing and infection. A VRAM flap has the most secure blood supply to the skin paddle. However, torsion should be avoided at the pedicle after full release of the rectus abdominis muscle at its origin at the pubic bone. Therefore, if length permits, which it usually does, it is advisable to leave the distal muscular attachment intact, especially when the patient is placed in a prone or lateral position during an abdominoperineal rectum amputation (Glatt et al, 2006). The musculocutaneous gracilis flaps carry a substantial risk of distal skin necrosis. This area is the deepest point of the newly shaped vaginal cone and difficult to treat with nonconservative measures after insertion into the pelvis. Side-wall restoration with an IGAP flap often collapses because of the intrinsic bulk of the flap in some patients. Several longterm complications have been described. Vaginal dryness is the most frequent complication because of inadequate secretion. Hypertrophy or dysesthesia at the scars may be significant. The neovagina is often too small after collapse and contraction. 


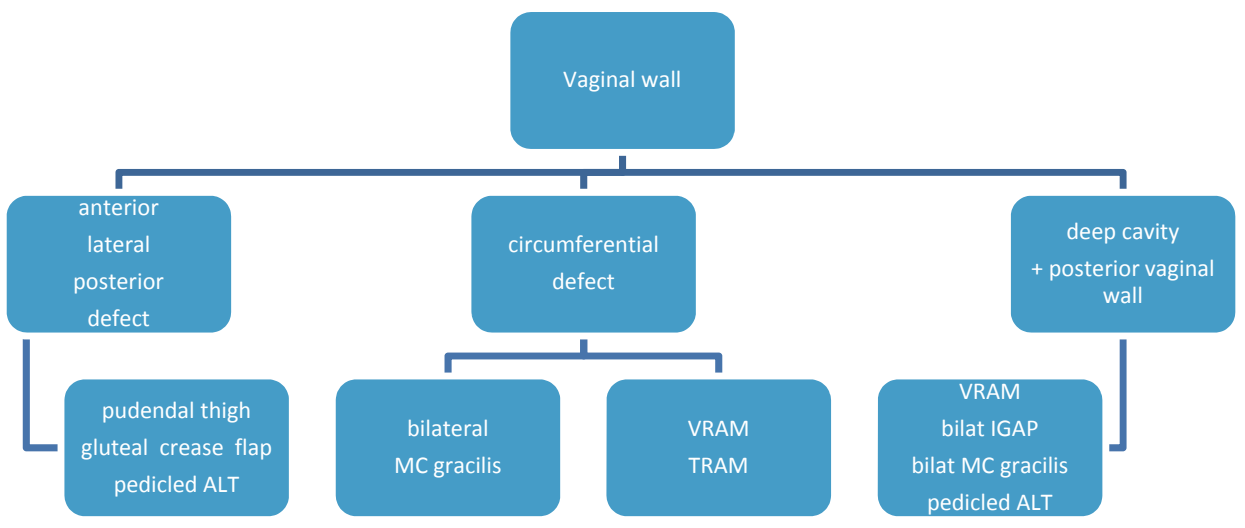

Fig. 6. Algorithm for vaginal wall reconstruction. ALT: anterolateral thigh flap. MC: myocutaneous, VRAM: vertical rectus abdominis muscle flap, TRAM: transverse rectus abdominis musculocutaneous flap, bilat IGAP: bilateral inferior gluteal artery perforator flap.

\subsection{Large composite defects of the perineal wall}

Most colorectal carcinomas with limited soft-tissue defects of the perineal wall are treated with primary closure of the neighboring tissue layers. However, tissue breakdown often occurs and poses a difficult reconstructive option because of scarring and tissue contracture.

Therefore, there is a tendency for closure of the perineal wall with locoregional, wellvascularized tissues, taking into consideration the fair outcome obtained with more extensive extirpation of colorectal cancer. Reconstructive options must address the dead space while inhibiting the herniation of the abdominal organs and introduce wellvascularized fasciocutaneous tissues in the perineal wall to prevent skin breakdown and fistulization (Fig. 7).

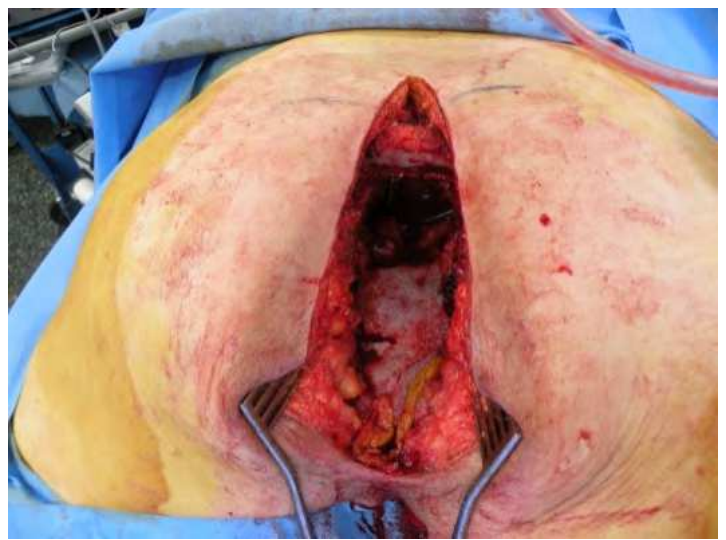

Fig. 7. A deep perineal defect requires obliteration of the pelvic cavity. 
In addition, advanced colorectal cancer frequently involves the posterior vaginal wall, and carcinoma of the bladder may extend into the anterior vaginal wall, which further complicates the reconstruction.

Complications after surgical closure for extended abdominoperineal resection (APRA) and infralevatoric pelvic exenterations (TIPE) arise from non-collapsible dead space, the use of irradiated skin for closure and infection. Surgical reconstructive options should address these factors and also focus on donor-site morbidity and quality-of-life parameters concerning sexual function and body integrity.

\section{Identification of the problem}

There is a close relationship among the colorectal tissues, the vagina and the urinary bladder. A complex, dynamic support system of ligaments coordinates the topography and function of these organs. As a result, after surgical resection of a tumor in this region, the loss of integrity and function of one organ may result in the collapse, prolapse or herniation of the remaining organs into the rigid cone-shaped pelvis. If a herniation of bowels into the pelvic cavity exists, radiation therapy may result in dramatic fistulizations that are difficult to treat without new colectomies. Therefore, it is imperative that the introitus of the pelvic cavity is sealed in an efficient fashion and that the pelvic cavity is filled with wellvascularized tissues that may also provide closure of the perineal wall with tissues resilient against radiotherapy. For small defects, a primary closure may still be considered. However, for medium-sized and large defects a composite reconstruction is mandatory.

The preferred method to restore these complex defects should be selected based on the anatomical features of the defect, i.e., the required width of the perineal skin, the anticipated volume needed to fill the perineal cavity, the vaginal defect (partial or circumferential), and previous interventions that may have influenced the donor sites. Based on these reconstructive aims, donor tissues are selected based on their intrinsic features such as pedicle length, quality and width of skin, tissue bulk and donor-site morbidity.

The abdominal wall and thigh area harbor a multitude of locoregional flaps that have been reported as used in the context of perineal and vaginal reconstruction. In comparison with free flaps, treatment with pedicled locoregional flaps is preferred, especially for mediumsized defects. Even for large, complex defects, there is a renewed interest in using locoregional pedicled flaps to restore the perineal wall because of our better understanding of the vascular perfusion of these flaps by their perforators. Harvesting of composite locoregional flaps therefore does not necessarily lead to significant donor-site morbidity if certain technical refinements are included in the flap harvest. Free flaps therefore are only indicated after pelvic exenterations or extended defects when no locoregional tissues are available because of previous interventions.

\section{Reconstructive options}

Long bilateral myocutaneous gracilis flaps have been considered as the workhorse for large defects of the perineal wall. However because of the lack of tissue bulk, these flaps do not fill a deep cavity efficiently, and the longitudinally aligned skin island is randomly vascularized in its distal section. Furthermore, to obtain a symmetric alignment of tissues, a bilateral flap is mandatory. For smaller perineal wounds including a circumferential vaginal defect, however, a bilateral myocutaneous gracilis flap is still useful. The donor site is small, although the scars may widen. The distal skin island is not always reliable, but vascularization may be improved by incorporating more fascia. 
The vertical rectus abdominis musculocutaneous flap displays robust vascularization and is characterized by large tissue bulk. The flap can be harvested on its inferior epigastric vascular pedicle. The skin island is oriented vertically aligning the median laparotomy incision. An anterior fascia-sparing approach is advised to diminish donor-site morbidity. This maneuver allows for minor resection of the anterior fascia, thereby removing the need for a mesh graft to restore the abdominal wall fascia. This strategy is highly recommended, especially for infected wounds. In addition, the proximal skin island can be extended as far as the posterior axillary line as proposed by Taylor et al. More recently, vascular angiographic studies demonstrated that multiple linking vessels exist between vertical and extended oblique skin territories, even at a subdermal level, which allows the surgeon to leave the deep fascia in the transition zone intact and to diminish donor-site morbidity when harvesting a large flap( Butler et al, 2008). The VRAM flap can be used in the perineal area via an anterior suprapubic or trans-groin approach using a subcutaneous tunnel at the pivot point (Fig. 8). This external rotation is useful when a defect in the groin needs to be restored simultaneously, for instance, after an extensive lymph node resection. Because of the external arc of rotation, the proximal segment of the flap allows the restoration of the groin

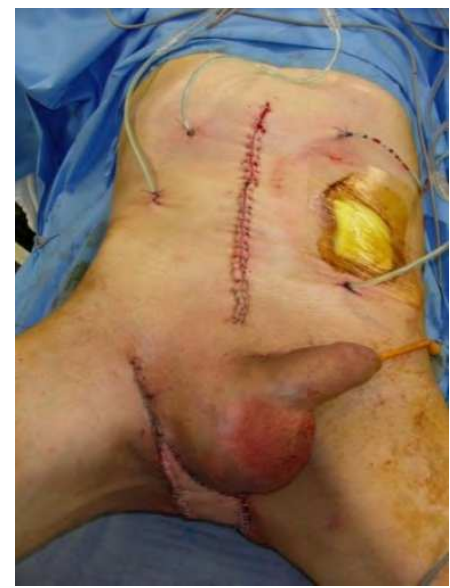

Fig. 8. VRAM flap externally rotated into the defect via a subcutaneous tunnel in the right groin. Part of the rectus abdominis muscle fills the deeper defect in the groin after lymphadenectomy.

area and the distal segment of the perineal defect. However because of the potentially increased donor-site morbidity for such defects, a pedicled anterolateral thigh flap may be the best option. Depending on the length-width ratio of the thigh, the anterolateral thigh flap may have sufficient length to fill the perineal cavity with well-vascularized tissues. When harvested distally on the thigh, the flap even may reach up posteriorly towards a partial sacrectomy defect. A vastus lateralis segment can be incorporated with the anterolateral thigh flap and offer supplementary tissue bulk when required. The major disadvantage of the anterolateral thigh flap is that the number and location of perforators to the skin paddle are not constant. Originally described as a septocutaneous perforator flap, musculocutaneous perforators are encountered in more than $60 \%$ of cases, which lengthens the time of harvest. In addition, the perforators quite often originate on the medial descending branch of the lateral circumflex 
vascular pedicle instead of the more conventional lateral descending branch. For these reasons, $\mathrm{CT}$ angiography is suggested to anticipate the topography of perforators in a fashion similar to that used for a DIEP perforator flap in breast reconstruction.

After an extended abdominoperineal rectum amputation, there is a wide and deep open pelvic introitus and a cavity that reaches the perineal wall. Adequate filling is mandatory to prevent the bowels from descending and exposure by radiotherapy. A transperitoneal course of the VRAM flap allows it to obliterate this pelvic cavity and to fill the dead space (Fig. 9). Usually, a traditional fascia-sparing VRAM flap is long enough to efficiently reach the posterior vaginal wall and the perineal wall down to the intergluteal crease (Fig. 10). If the defect travels more posteriorly, an extended VRAM is required.
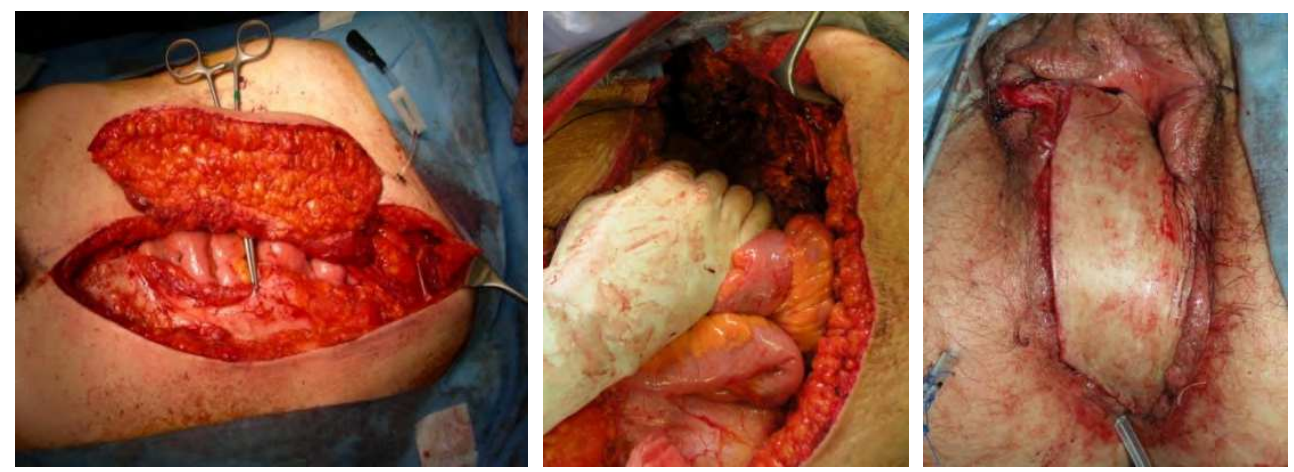

Fig. 9. Left: harvest of the VRAM vertical rectus abdominis musculocutaneous flap by fascia sparing approach. Middle: the VRAM flap is transferred via transabdominal approach into the pelvic cavity. Mark the deep inferior epigastric vascular pedicle at the upper right side under the retractor. Right: the VRAM flap has been tunneled to the perineum and only sutured distally. After verification that no traction is exerted on the vascular pedicle proximally, the skin island is remodeled according to the requirements for restoring the posterior vaginal wall and the perineal wall.
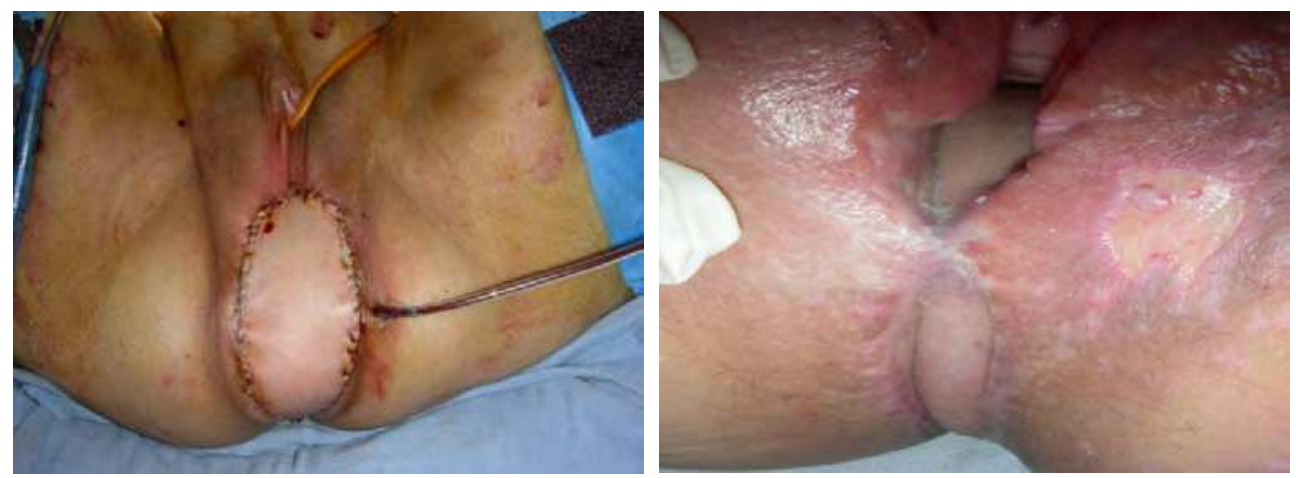

Fig. 10. Left: reconstruction of the perineal and posterior vaginal wall by transpelvic VRAM flap. Right: VRAM flap after 55 Gy local irradiation. The posterior vaginal lining remained soft, with a preserved circular vaginal configuration. The surrounding skin suffered from irradiation with significant erythema and skin erosions. 
Inferior gluteal artery-based perforator flaps (IGAP) are a good option to close the perineal defect when less volume is needed to fill the dead space in the perineal cavity. If the patient is positioned in the prone position or when previous surgery or a badly planned positioning of the colostomy and urostomy after a Bricker derivation excludes the use of a VRAM flap, a unilateral or bilateral IGAP flap is a good option. Based on perforators of the inferior gluteal vascular pedicle, the adipocutaneous flap can be harvested with a wide arc of rotation.

The superomedial segment of the IGAP flap rotates into the defect and is de-epithelialized (Fig. 11). An end-to-side suture of the contralateral gluteal skin to the IGAP flap allows closure and filling of the defect. In obese patients, the obtained tissue bulk of an IGAP flap can be substantial. Fig. 12 represents our current algorithm for large perineal defects (Vranckx et al, 2011)
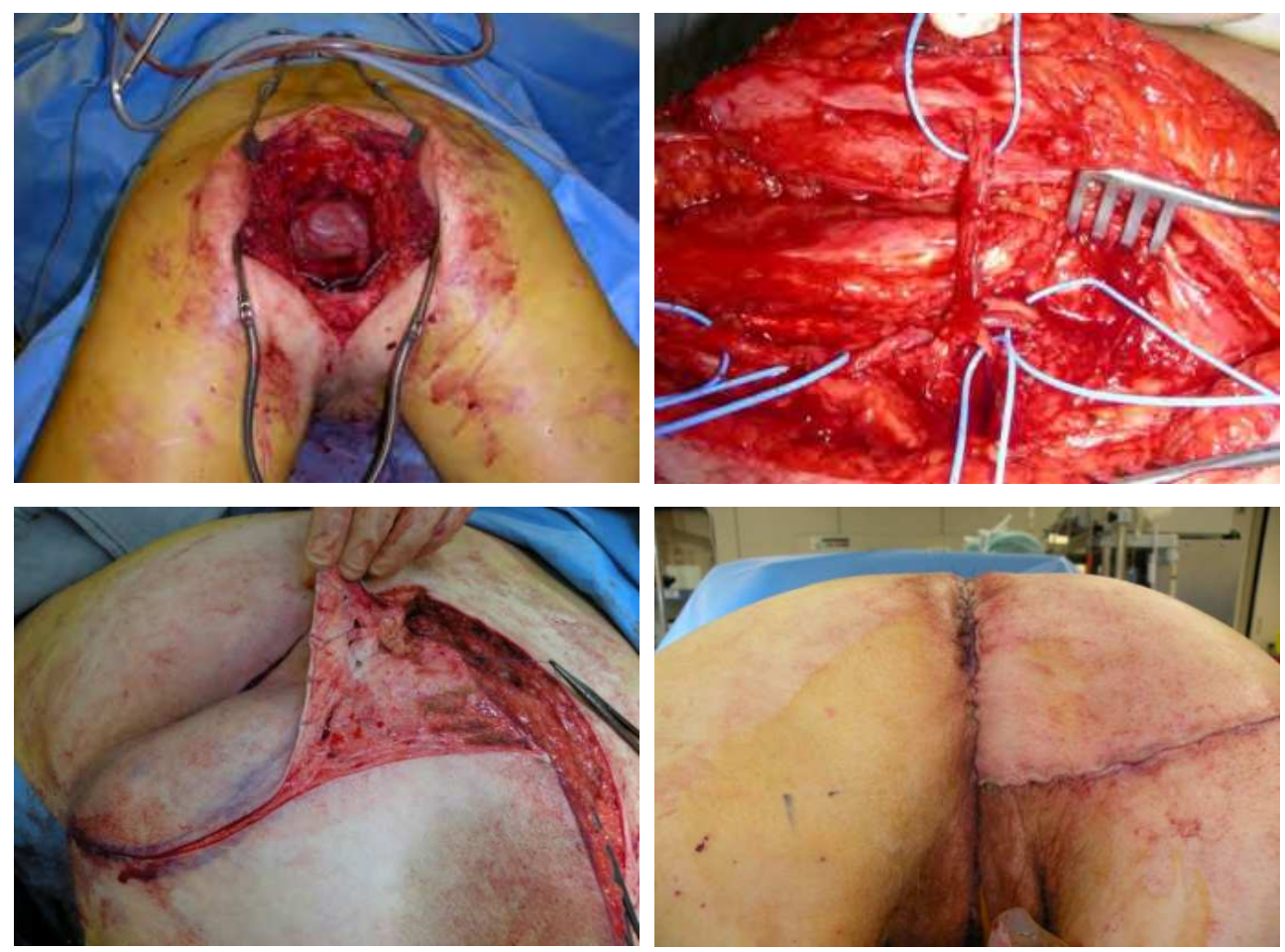

Fig. 11. Upper left: deep cavity after extended abdominoperineal rectum amputation. Upper right: an IGAP inferior gluteal artery perforator-based flap is harvested. One perforator is selected and further dissected to achieve optimal rotation. Lower left: the required segment has been de-epithelialized. Lower right: the de-epithelialized segment is sutured to the deep borders of the pelvic cavity. Skin closure is performed with an end-to-side suture to recreate the gluteal crease. 


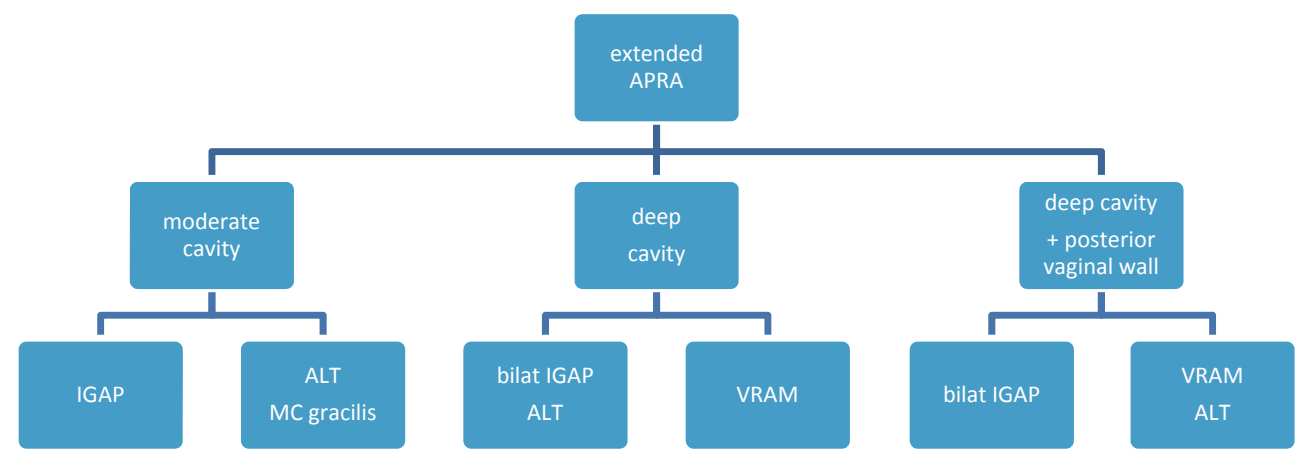

Fig. 12. Algorithm of the treatment of defects after extended abdominoperineal rectum amputation. A distinction is made between defects with a moderate pelvic cavity and deep cavities versus defects that require reconstruction of the posterior vaginal wall. IGAP: inferior gluteal artery perforator flap; ALT: anterolateral thigh flap: MC gracilis: myocutaneous gracilis flap; VRAM: vertical rectus abdominis myocutaneous flap.

\section{Reconstruction of the abdominal wall}

\subsection{Pathophysiology}

The abdominal wall is lined superiorly by the xiphoid process and the costal cartilage of ribs 7-12. The inferolateral border is lined by the inguinal ligament and medially by the pubis tubercle and pubic bone. A line from the midaxilla to the anterior superior iliac spine of the iliac crest delineates the lateral borders. The diamond-shaped abdominal wall consists of the peritoneum, three fascial layers and four significant muscles, a subcutaneous layer of variable thickness, Scarpa's fascia and the skin. The fascia layers of the external and oblique muscles and the transverse abdominis muscle fuse at the lateral border of the rectus abdominis muscle and form the deep fascia layer. The arcuate line halfway between the umbilicus and the pubic symphysis denotes the change in the composition of the rectus sheath. Above the arcuate line, the anterior fascia layer consists of the external and internal oblique muscle aponeuroses; below the arcuate line, the three aponeurotic layers form the anterior rectus sheet. Motor innervation to these muscles comes from the intercostal and subcostal nerves for the rectus abdominis muscle as well as from the iliohypogastric nerve for the external oblique muscle or the ilioinguinal nerve for the internal oblique muscle. The nerves should be preserved not only for sensation but especially to maintain the motor function of the abdominal wall. The structural integrity of all of these layers is important in the majority of biomechanical body movements, especially walking, bending, climbing and posture, and is also elementary in supporting the visceral functions of digestion, micturition, defecation, respiration and expectoration. Tumor extirpation and trauma are the most common causes of full-thickness abdominal wall defects. Necrotizing fasciitis, irradiation and burns may cause rather extensive superficial defects (Fig. 13). 


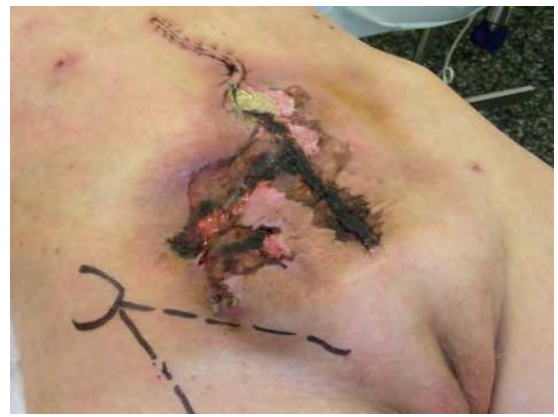

Fig. 13. Left: Irradiation wound after laparotomy for abdominal wall sarcoma with resection and primary closure.

Reconstruction of the abdominal wall focuses on the restoration of structural integrity and function and the prevention of visceral eventration. The available options depend on multiple parameters such as the location and size of the defect, BMI of the patient, scars from previous interventions, irradiation and presence of a colostomy or urostomy (Gottlieb et al., 1990). Matheset al. described the types of defects based on the defect components: type I defects with hernia defects and intact stable skin coverage and type II defects with hernia and unstable or absent skin coverage (Mathes et al., 2000). Defects were also assigned to zones: zone 1A represents the upper midline of the abdomen, zone $1 \mathrm{~B}$ the lower midline area, zone 2 the upper quadrant and zone 3 the lower quadrant (Fig. 14).
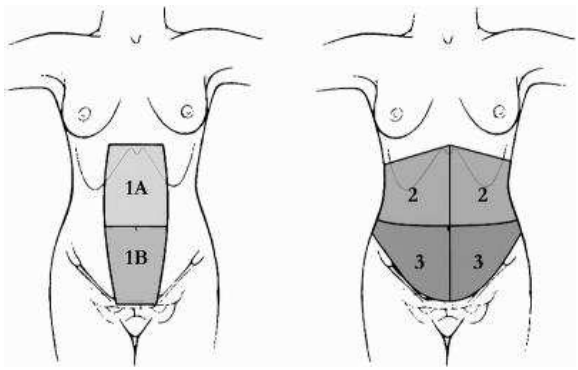

Fig. 14. Reconstructive zones of the abdomen. (Mathes . et al. Ann. Surg. 232; 586-596.)

Hurwitz described seven anatomic reconstructive subunits (Hurwitz \& Hollins, 1994). Rohrich at al. described a six-subunit scheme delineating the midline and lateral upper, middle and lower thirds and proposed a treatment algorithm based on these zones (Rohrich et al., 2000). The most difficult zones to treat are zone IA or upper-midline defects because locoregional flaps from the thigh or the back are located distally. To treat such patients, zone-free flaps with vascular anastomosis to the deep inferior epigastric, superior epigastric or internal mammary vascular pedicle have been suggested. Most defects are type I incisional hernias with stable skin coverage and only require mesh coverage (Pless TK \& Pless JE, 1993). There are currently many different types of meshes available. The risk of infection plays an important role in selection of the appropriate treatment strategy. Polypropylene is commonly used for fascia repair. This mesh induces an intense fibrovascular infiltration and incorporates into the surrounding tissues, leading to a strong repair, but it is also associated with adhesions to the intra-abdominal viscera with consequent frequent formation of enterocutaneous fistulas. Non- 
absorbable synthetic meshes are largely intolerant to an infected environment such as the environment that persists after the resection of abdominal wall tumors. New-generation biologic meshes (such as human acellular dermal matrix, which is derived from human cadaveric dermis) can be utilized in a contaminated milieu (Fig. 15). They are the first choice in the treatment of complex wounds after chronic exposure to provide the fascia layers with sufficient strength and adequate skin coverage (Breuing et al., 2010).
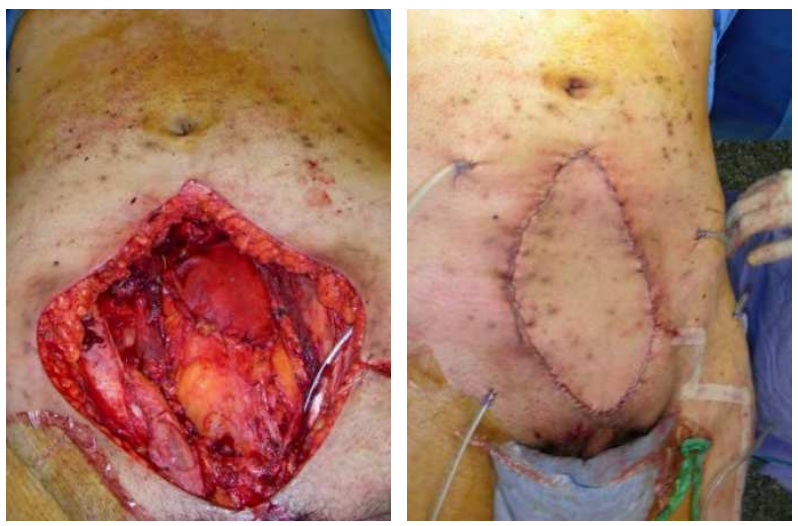

Fig. 15. Left: Biologic mesh restores the fascia gap before closure with a pedicled anterolateral thigh flap (right).

The treatment of type-II defects depends largely on the central tissue gap. The overall failure of treatment is often attributed to primary closure under tension, which causes midline necrosis of the abdominal wall. Primary closure should therefore be limited to patients with small defects and few associated risk factors for poor wound healing. Immediate reconstruction is the strategy of choice in primary extirpation surgery or eventration repair. A delayed repair is advisable when the wound is infected or when the patient is unstable and the defect is extensive. Vacuum-assisted closure can be of great value, and abdominal dressings have been developed to assist in progressive wound conditioning and prevent the abdominal muscular layers from retracting( Fig. 16).
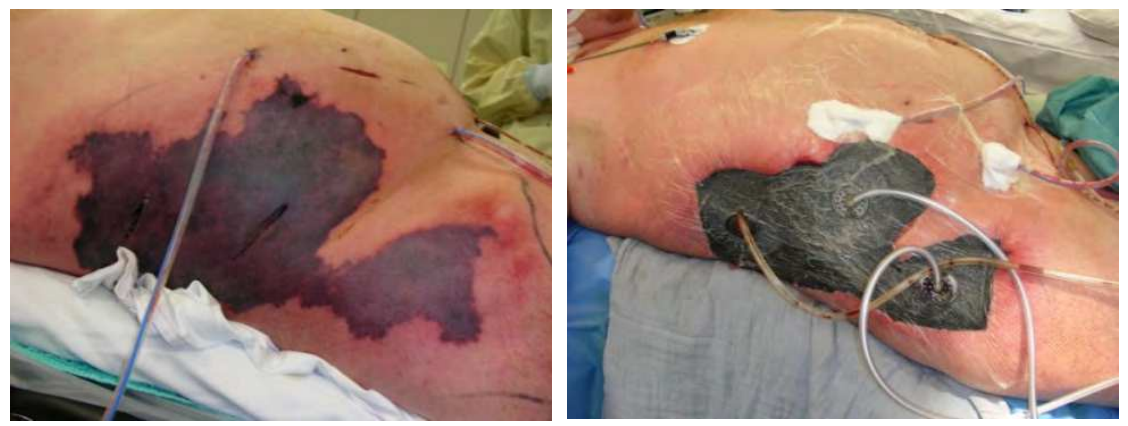

Fig. 16. Left. Vacuum-assisted closure device on zone III of the abdomen and on the lateral thighs after serial debridements for necrotizing fasciitis as a result of colon anastomotic leakage and resulting fistula to the skin. 
In type II composite defects, component release techniques are the most frequently used approach to treatment (Ramirez et al., 1990). However, when excessive traction is exerted on the midline tissues, morbidity after a traditional Ramirez procedure is significant. With current perforator dissection techniques, relevant perforators to the abdominal wall skin are preserved during a component release procedure. Sufficient vascularization to the abdominal wall tissues ensures that closure can be performed under tension despite substantial undermining forces (Shestaq et al., 2000).

Large and composite defects after tumor extirpation and in the presence of a colostomy and urostomy still pose a surgical challenge. These defects require the introduction of tissues to bridge the gap. Local full-thickness abdominal wall rhomboid flaps and extended abdominal wall flaps may achieve closure of the defect but at the cost of further abdominal wall weakening. Pedicled uni-or bilateral tensor fascia lata flaps have long been used as a standard approach to restore the abdominal wall defect because thigh flaps leave the remaining abdominal wall intact (Williams et al., 1998). For meso-and epigastric defects, however, the harvest should include distal fascia to achieve sufficient length. Distally, the fascia is thin and less vascularized, and it does not restore function and aesthetic appearance, especially in more obese patients and defects located in the upper midline or supralateral zones.

The rectus femoris myocutaneous flap introduces more voluminous tissues and allows the closure of the donor site. The rectus femoris muscle is the most significant quadriceps muscle, and its harvest may diminish knee extension. In addition, the donor scar located anteriorly on the thigh is conspicuous when a large skin paddle has been incorporated. Because the transition zone of the quadriceps muscle and tendinous segment at the midline of the thigh should be kept intact to preserve the leverage of the quadriceps during knee extension, the harvest should stop at the distal two-thirds of the mid-thigh, which does not allow a sufficient length to reach upper-midline defects.

The anterolateral thigh is a common donor zone for free flaps used in lower-limb and head and neck reconstruction (Wei et al., 2002). Recent reports describe its use in perineal reconstructions $\mathrm{Yu}$ et al. 2002, Luo et al., 2000). Donor-site morbidity is minimal if a perforator-based anterolateral thigh flap is harvested (Lipa et al., 2005, Tsuji et al., 2008). The vascularization pattern of this flap allows for a distal harvest on the thigh based on available perforators. A multitude of flaps can be designed based on these perforators. A useful combination in the anterolateral thigh is that of the skin paddle and the vastus lateralis muscle, which can be used in extensive defects (Posh et al., 2005). Sasaki and Kimata used free anterolateral thigh flaps in combination with a tensor fascia lata musculocutaneous flap to restore a large abdominal wall defect (Sasaki K. et al., 1998, Kimata et al., 1999) and concluded that the ALT flap with or without the TFL was superior to the TFL alone for the reconstruction of large abdominal wall defects.However, the anterolateral thigh flap can be raised distally on the thigh. The vascular pedicle is long and allows the harvesting of a large pedicled flap. To reach the abdominal wall as a pedicled flap, tunneling should be performed under the rectus femoris and sartorius muscles. During this maneuver, it is critical to not harm other femoral nerve branches to avoid a further decline in quadriceps function (Fig. 17). Thus far, the use of the anterolateral thigh flap for abdominal wall reconstruction is anecdotal, but those authors who have used the ALT in this setting claim that the ALT can reach all abdominal wall regions as a pedicled flap (Lannon et al., 2011, Vranckx et al., 2011). 

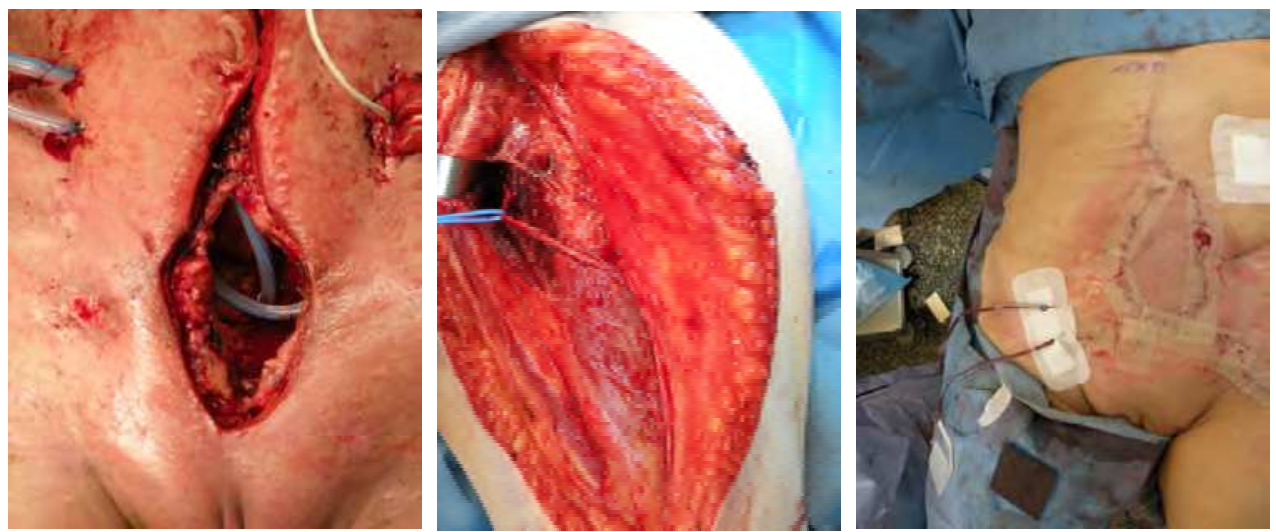

Fig. 17. ALT perforator flap for abdominal wall reconstruction. Left: abdominal wall fullthickness defect. Mid: anterolateral thigh flap harvested with the skin paddle perfused on one large perforator branch, which is followed to the origin of the descending branch into the lateral circumflex femoral vascular pedicle. At the same time, a segment of vastus lateralis is harvested with its femoral motor nerve intact. Right: flap closes the defect with like-with-like tissues.

The abdominal wall participates intensively in posture and has a synergistic function in a multitude of movements. Functional restoration of the abdominal wall is therefore an ultimate aim in reconstructive surgery. Dynamic activities may be restored using a layered wound closure method to identify and separate all muscle components (Pless T \& Pless J, 2005). For large defects with extensive tissue loss, coaptation of the external oblique muscle continuity must be included, and dynamic tissues must be introduced into the defect. Koshima demonstrated that a pedicled rectus femoris muscle flap restored contractile activities in the abdomen (Koshima Iet al. 1999). Sasaki used a free TFL flap (Sasaki et al., 1998) and Ninkovic used a free, innervated latissimus dorsi flap (Ninkovic et al., 1998) to restore the contractile activities in the abdominal wall. They achieved excellent dynamic results. However, free flaps require a lag time during which the abdominal wall is weakened and herniation may (re)occur. Vranckx uses pedicled musculocutaneous anterolateral thigh flaps to restore the abdominal wall defect in a like-with-like fashion (Fig. 18). Femoral nerve branches to the harvested vastus lateralis muscle are left intact during the transfer. The muscle segment restores and bridges the muscular gap. The thigh fascia with the tractus iliotibialis is sutured to the fascial boundaries of the defect. The anterolateral thigh skin paddle restores the abdominal wall skin defect (Vranckx et al., 2010). The authors achieved excellent dynamic results over a 1-year follow up as determined by dynamometric analysis. Future aims should further focus on the dynamic restoration of abdominal wall defects using donor tissues with minimal donor-site morbidity (Fig. 18).

Conclusion. The reconstruction of complex abdominal wall defects is a veritable challenge. The aim of the restoration is the preservation of abdominal wall integrity and function while avoiding the herniation of the abdominal wall content. Type I defects consisting of herniation with adequate skin coverage require fascia repair, and various techniques are described. For small to moderate Type II full-thickness defects, perforator-preserving component-release techniques are efficient as long as excessive traction on the midline is avoided. For large 
composite defects, tissues should be introduced into the defect to restore the integrity of the abdominal wall. A dynamic instead of static reconstruction is the ultimate aim.
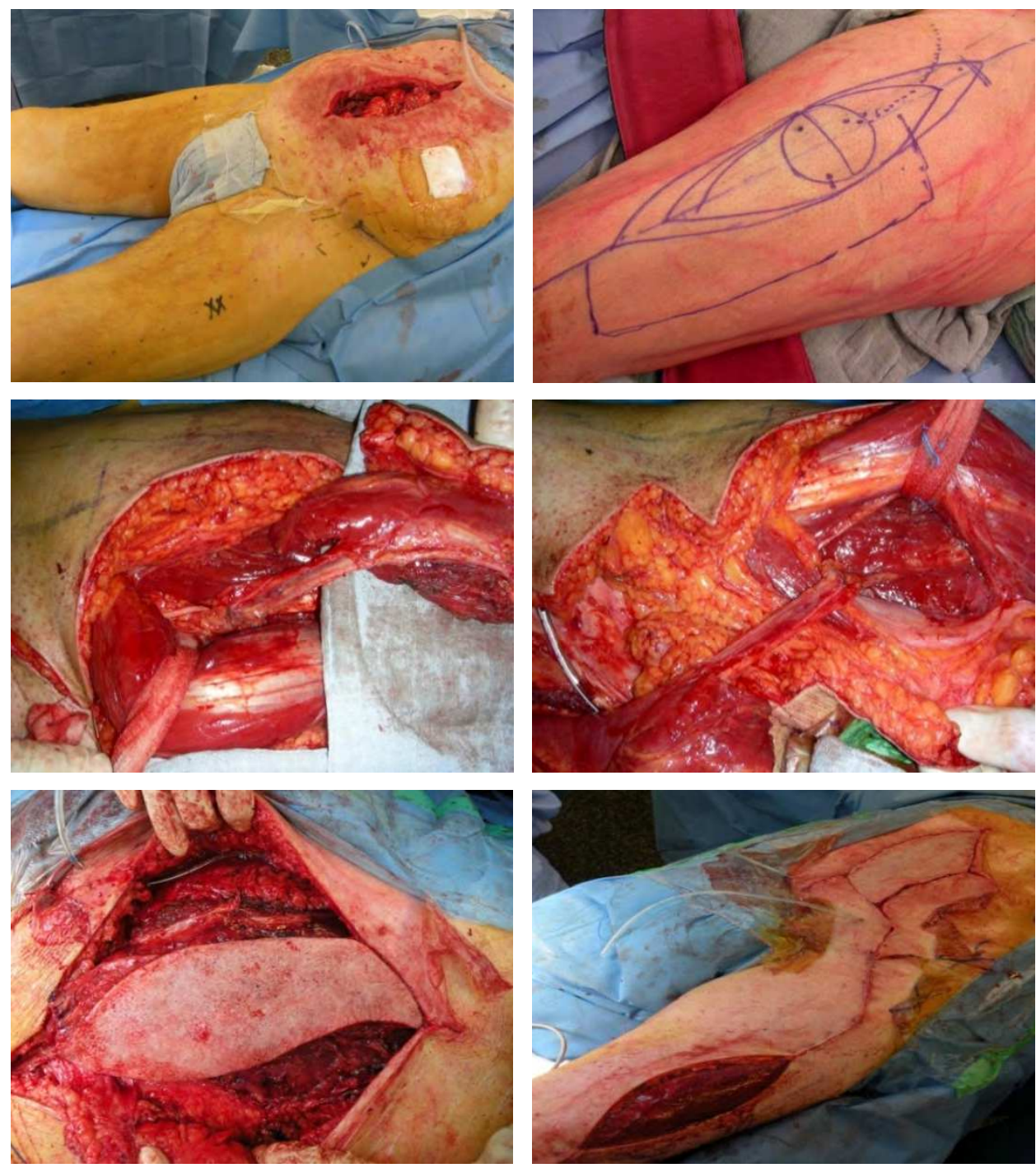

Fig. 18. Upper left: Abdominal wall defect in zones IA and IB. The most proximal part reaches the xyphoid process. Upper right: Anterolateral thigh flap with vastus lateralis segment harvested from the left thigh. Mid-left: The pedicle is dissected to its origin just lateral of the rectus femoris muscle. Mid-right: the ALT/VL flap is tunneled under the rectus femoris muscle to medialize the pivot point of the pedicle. Lower left: the ALT/VL flap covers the whole defect up to the xyphoid process with ease without any traction on the muscle, fascia or skin paddle (nb. xyphoid process at the right side of the picture). Lower right. After suturing of the flap into the defect. The donor site just before skin grafting. 


\section{References}

Abbott DE., Halverson AL., Wayne JD., et al. The oblique rectus abdominal myocutaneous flap for complex pelvic wound reconstruction. Dis.Colon Rectum; 51:1237-1241, 2008

Breuing K., Butler CE., Ferzoco S., et al. Ventral Hernia Working Group. Incisional ventral hernia's: review of litterature and recommendations regarding the grading and technique of repair. Surgery 148: 544-558, 2010

Butler CE., Gundeslioglu AO., Rodriguez-Bigas MA. Outcome of immediate vertical rectus abdominis myocutaneous flap reconstruction for irradiated abdominoperineal resection defects.J.Am.Col.Surg.; 206: 694-703, 2008

Friji MT., Suri MP., Shankhdhar VK., Ahmad QG., Yadav PS. Pedicled anterolateral thigh flap: a versatile flap for difficult regional soft tissue reconstruction. Ann.Plast.Surg., 64, 458-61.; 2010

Glatt BS., Disa Jj. Et al. Reconstruction of extensive partial or total sacrectomy defects with a transabdominal vertical rectus abdominis myocutaneous flap. Ann. Plast.Surg; 56: 526531,2006

Gottlieb JR., Engrav LH., Walkinshaw MD et al. Upper abdominal wall defects: immediate or staged reconstruction? Plast.Reconstr.Surg; 86:281, 1990

Hurwitz DJ., Hollins RR. Reconstruction of the abdominal wall and groin. In M.Cohen (Ed), Mastery of Plastic and Reconstructive surgery, Vol 1, 1st Ed. Boston: Little, Brown, 1994

Kimata Y., Uchiyama K.,Sekido M et al. Anterolateral thigh flap for abdominal wall reconstruction. Plast.Reconstr.Surg.103: 1191-1197, 1999

Koshima I., Moriguchi T., Inagawa K., Urushibara K. Dynamic reconstruction of the abdominal wall using a reinnervated free rectus femoris muscle transfer. Ann.Plast.Surg.43:199-203, 1999

Lannon DA., Ross GL., Addison PD., Novak CB., Lipa JE., Neligan PC. Versatility of the pedicled anterolateral thigh flap and its use in complex abdominal and pelvic reconstruction. Plast.Reconstr.Surg., 127, 677-88,2011

Lannon DA.,Ross GL., Addisson PD., Novak CB.,Lipa JE., Neligan PC. Versatility of the pedicled anterolateral thigh flap and its use in complex abdominal and pelvic reconstructions.Plast.Reconstr.Surg. ;127,677-88, 2011

Lefevre JH., Parc Y et al. Abdomino-perineal resecton for anal cancer. Ann.Surg.; 250: 707-711, 2009

Lesavoy MA., Carter EJ. Vaginal reconstruction. In Raz S, ed: Female Urology, 2nd ed. Philadelphia,WB Saunders;605-616,1996

Lipa JE., Novak CB., Binhammer PA. Patient-reported donorsite morbidity following anterolateral thigh free flaps. J.Reconstr.Microsurg. 21; 365-370,2005

Luo S., Raffoul W., Piaget F., Egloff DV. Anterolateral thigh fasciocutaneous flap in the difficult perineogenital reconstruction. Plast.Reconstr.Surg. 105:171-173,2000

Mathes SJ., Steinwald PM.,Foster RD.,Hofffman WY.,Anthony JP. Complex abdominal wall reconstruction: a comparison of flap and mesh closure. Ann.Surg. 232: 586-96,2000

Ninkovic M., Kronberger P., Harpf C. et al. Free innervated latissimus dorsi musculocutaneous flap for reconstruction of full-thickness abdominal wall defects. Plast.Reconstr.Surg.; 101:971,1998

Nisar PJ., Scott HJ. Myocutaneous flap reconstruction of the pelvis after abdominoperineal excision. Colorectal Dis.; 11, 806-816, 2009

Park JY., Choi $\mathrm{HJ}$ et al. The role of pelvic exenteration and reconstruction for treatment of advanced or recurrent gynaecologic malignancies: analysis of risk factor predicting recurrence and survival. J.Surg. Oncol.; 96, 560-568,2007

Pless TK., Pless JE. Giant ventral hernia's and their repair. A 10 year follow-up study. Scand.HJ.Plast. Reconst.Surg.Hand.Surg.; 27:311,1993 
Posh NA., Mureau MA., Flood SJ, Hofer SO. The combined free partial vastus lateralis with anterolateral thigh flap reconstruction of extensive composite defects.Br.J.Plast.Surg. 58: 1095-1103,2005

Pusic AL., Mehrara BJ. Vaginal reconstruction: an algorithm approach to deect classification and flap reconstruction. J. Surg. Oncol.; 94: 515-521, 2006

Ramirez OM., Ruas E., Dellon AL: Component separation method for closure of abdominal wall defects: an anatomic and clinical study. Plast.Reconstr.Surg.; 86:519,1990

Reddy VR., Stevenson TR, Whetzel TP. A 10-year experience with the gracilis myofasciocutaneous flap. Plast.Reconstr. Surg.; 117: 635-639, 2006

Rohrich RJ., Lowe JB., Hackney FL., Bowman JL.,Hobar PC. An algorithm for abdominal wall reconstruction. Plast. Reconstr. Surg.105: 202-216,2000

Sasaki K., Nozaki M., Nakazawa H., Kikuchi Y.,Huang T. Reconstruction of a large abdominal wall defect using a combined free tensor fascia lata musculocutaneous flap and anterolateral thigh flap. Plast.Reconstr. Surg. 102: 2244-2252,1998

Shestaq KC., Edington HJD., Johnson RR. The separation of anatomic components technique for the reconstruction of massive midline abdominal wall defects: anatomy,surgical technique, applications and limitations revisited. Plast. Reconstr. Surg. 105: 731-38,2000

Taylor GI, Corlett R., Boyd JB. The extended deep inferior epigastric flap: a clinical technique. Plast.Reconstr.Surg. 72:751-765, 1983.

Tobin GR, Day TG. Vaginal and pelvic reconstruction with distally based rectus abdominis myocutaneous flaps. Plast.Reconstr.Surg.; 81: 62-73, 1988

Tsuji N., Suga H., Uda K., et al. Functional evaluation of anterolateral thigh flap donor sites: isokinetic torque comparisons for knee function. Microsurgery 28: 233-7,2008

Villa M., Saint-Cyr M., Wong C., Butler CE. Extended vertical rectus abdominis myocutaneous flap for perlvic reconstruction: three-dimensional and four-diensional computed tomography angiographic perfusion study and clonical outcome analysis.Plast. Reconstr. Surg. 127:200, 2011

Vranckx J.J., Veys B., D’Hoore A., Joniau S.,Nanhekhan L., Fabré G., Segers K., Van Brussel M., Vandevoort M., Reconstruction of perineum after extended APRA and infralevatoric pelvic exenteration. Proceedings WSRM2011, World Society of Reconstructive Microsurgery,pp. 59-64, ISBN 978-88-7587-612-8, Helsinki(Finland), June 29-July 2, 2011

Vranckx JJ., Miserez M., D’Hoore A., Nanhekhan L., SegersK., Fabré G., Vandevoort M. Dynamic reconstruction of full thickness abdominal wall defects by innervated musculocutaneous flaps from the anterolateral thigh. Proceedings WSRM2011, World Society of Reconstructive Microsurgery,pp. 65-69, ISBN 978-88-7587-612-8, Helsinki(Finland), June 29-July 2, 2011

Wagstaff MJD., Rozen WM et al. Perineal and posterior vaginal wall reconstruction with superior and inferior gluteal artery perforator flaps. Microsurgery; 29: 626-629, 2009

Wei FC., Jain V., Celik N., et al. Have we found an ideal soft-tissue flap? An experience with 672 anterolateral thigh flaps. Plast.Reconstr. Surg. 109: 2219-2226,2002

Whetzel TP., Lechtman AN. The gracilis myofasciocutaneous flap: vascular anatomy and clinical application. PLAst.Reconstr. Surg.; 99: 1642-1652, 1997

Williams JK., carlson GW.,de Chalain T., Howell R., Coleman JJ. Role of the tensor fascia latae in abdominal wall reconstruction.Plast.Reconstr.Surg.101:713-8,1998

Yu P., Sanger JR.,Matloub HS.,Gosain A., Larson D. Anterolateral thigh fasciocutaneous island flaps in perineoscrotal reconstruction. Plast.Reconstr.Surg. 109; 610-6,2002 


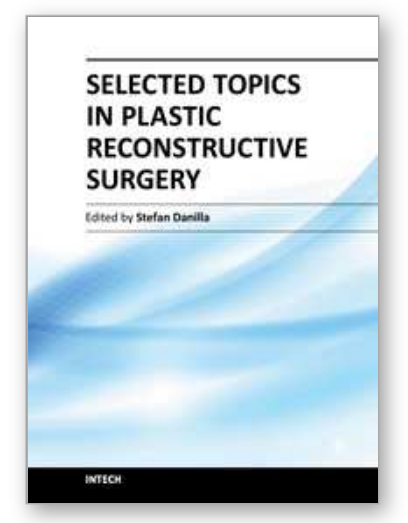

\author{
Selected Topics in Plastic Reconstructive Surgery \\ Edited by Dr Stefan Danilla
}

ISBN 978-953-307-836-6

Hard cover, 242 pages

Publisher InTech

Published online 20, January, 2012

Published in print edition January, 2012

Plastic Surgery is a fast evolving surgical specialty. Although best known for cosmetic procedures, plastic surgery also involves reconstructive and aesthetic procedures, which very often overlap, aiming to restore functionality and normal appearance of organs damaged due to trauma, neoplasm, ageing tissue or iatrogenesis. First reconstructive procedures were described more than 3000 years ago by Indian surgeons that reconstructed nasal deformities caused by nose amputation as a form of punishment. Nowadays, many ancient procedures are still used like the Indian forehead flap for nasal reconstruction, but as with all fields of medicine, the advances in technology and research have dramatically affected reconstructive surgery.

\title{
How to reference
}

In order to correctly reference this scholarly work, feel free to copy and paste the following:

J.J. Vranckx and A. D'Hoore (2012). Reconstruction of Perineum and Abdominal Wall, Selected Topics in Plastic Reconstructive Surgery, Dr Stefan Danilla (Ed.), ISBN: 978-953-307-836-6, InTech, Available from: http://www.intechopen.com/books/selected-topics-in-plastic-reconstructive-surgery/reconstruction-ofperineum-and-abdominal-wall

\section{INTECH}

open science | open minds

\section{InTech Europe}

University Campus STeP Ri Slavka Krautzeka 83/A 51000 Rijeka, Croatia Phone: +385 (51) 770447

Fax: +385 (51) 686166 www.intechopen.com

\section{InTech China}

Unit 405, Office Block, Hotel Equatorial Shanghai No.65, Yan An Road (West), Shanghai, 200040, China 中国上海市延安西路65号上海国际贵都大饭店办公楼405单元 Phone: +86-21-62489820

Fax: $+86-21-62489821$ 
(C) 2012 The Author(s). Licensee IntechOpen. This is an open access article distributed under the terms of the Creative Commons Attribution 3.0 License, which permits unrestricted use, distribution, and reproduction in any medium, provided the original work is properly cited. 